\title{
INFORMALIDADE, ESTABILIDADE E PRECARIEDADE Uma análise sequencial das trajetórias profissionais ao longo das últimas décadas
}

\author{
Vasco Ramos \\ ICS-UL, Lisboa, Portugal
}

\begin{abstract}
Resumo A imprevisibilidade dos percursos profissionais na era do capitalismo pós-fordista é uma problemática amplamente discutida na sociologia contemporânea. Partindo da segunda metade do século XX, o artigo contextualiza a discussão no contexto português. Mobilizando o conceito de trajetória profissional, desenvolvido a partir da análise sequencial às trajetórias de portugueses de três coortes etárias, oferece-se uma tipologia dos percursos que articula modalidades contratuais e atividade profissional. Os resultados revelam ampla variedade de trajetórias e a segmentação entre percursos com diferentes graus de vulnerabilidade contratual.
\end{abstract}

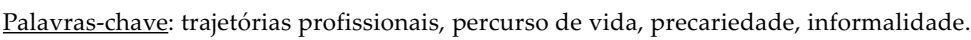

Abstract The issue of the unpredictability of occupational paths in the post-Fordist capitalist era has been widely discussed in contemporary sociology. Beginning with the second half of the $20^{\text {th }}$ century, the article contextualises this debate in the Portuguese case. Mobilising the occupational trajectory concept, which it develops using a sequential analysis of the trajectories of three Portuguese age cohorts, it offers a path typology that articulates contractual formats and work. The results reveal a wide variety of trajectories and a segmentation of paths into different degrees of contractual vulnerability.

Keywords: occupational trajectories, life path, precarity, informality.

Résumé L'imprévisibilité des parcours professionnels à l'ère du capitalisme postfordiste est une problématique amplement discutée dans la sociologie contemporaine. L'article part de la seconde moitié du XXe siècle pour resituer la discussion dans le contexte portugais. En développant le concept de trajectoire professionnelle à partir de l'analyse séquentielle des trajectoires de Portugais de trois tranches d'âge, il propose une typologie des parcours qui associe modalités contractuelles et activité professionnelle. Les résultats révèlent une grande variété de trajectoires et de segmentations entre parcours présentant différents degrés de vulnérabilité contractuelle.

Mots-clés: trajectoires professionnelles, parcours de vie, précarité, informalité.

Resumen La imprevisibilidad de los trayectos profesionales en la era del capitalismo post-fordista es una problemática ampliamente discutida en la sociología contemporánea. Partiendo de la segunda mitad del siglo XX, el artículo contextualiza la discusión en el panorama portugués. Movilizando el concepto de trayectoria profesional, desarrollado a partir del análisis secuencial a las trayectorias de portugueses de tres cohortes de edad, ofrece una tipología de los trayectos que articula modalidades contractuales y actividad profesional. Los resultados revelan una amplia variedad de trayectorias y la segmentación entre recorridos con diferentes grados de vulnerabilidad contractual.

Palabras-clave: trayectorias profesionales, trayecto de vida, precariedad, informalidad.

\section{Introdução}

Com o fordismo estabeleceu-se uma articulação entre as relações de produção e os modos de consumo que conduziu à estabilização relativa das relações laborais e à universalização do trabalho assalariado. Sob a égide do estado, o "contrato" entre 
trabalho e capital assegurou um período de crescimento económico, pleno emprego e baixa conflitualidade social. A estabilidade das relações laborais contribuiu para que trabalho passasse a ser sinónimo de emprego (Castel, 2012).

A possibilidade de progressão profissional foi real em muitas organizações no quadro do capitalismo fordista. A progressão tinha implícita uma promessa de mobilidade social ascendente e era comum que o percurso profissional fosse integralmente desenvolvido numa só empresa. O contexto institucional fordista edificou também uma divisão fortemente genderizada entre trabalho assalariado e trabalho familiar, cristalizado no modelo de homem ganha-pão e no equivalente cuidador feminino.

Contudo, sabe-se hoje que o acesso à relação de emprego fordista foi mais limitado do que algumas narrativas advogam. Efetivamente os pressupostos da estabilidade profissional estavam reservados às profissões mais prestigiadas e melhor remuneradas. Na prática, a relação salarial e contratual fordista terá sido experimentada por um grupo restrito de trabalhadores, sobretudo homens, brancos e com um módico de qualificações escolares/profissionais (Bradley et al., 2000).

Este artigo situa a discussão em torno da (des)regulação e flexibilização do trabalho no contexto português das últimas décadas. Em primeiro lugar, face à amplitude das transformações na esfera do trabalho e do emprego, procura-se identificar as características paradigmáticas dos percursos profissionais em Portugal. Em segundo lugar, investiga-se a pertinência das teses que apontam para uma precarização generalizada. Questiona-se igualmente em que medida é lícito, no contexto português, associar épocas passadas à estabilidade no emprego. Por fim, discute-se em que medida as trajetórias profissionais se relacionam com processos de reprodução e estratégias de mobilidade social.

Estas questões são investigadas adotando uma estratégia metodológica centrada nos percursos individuais. Partindo de dados de uma recente investigação sobre o percurso de vida em Portugal, caracterizam-se as trajetórias profissionais de indivíduos nascidos em três coortes etárias e identificam-se diferentes tipos de trajetórias. A discussão dos resultados salienta a importância da regulação institucional das relações laborais na estabilidade dos percursos, bem como evidencia os efeitos da fragmentação do mercado de trabalho sobre as trajetórias individuais.

\section{Do emprego estável às trajetórias profissionais incertas}

A reconfiguração do papel do estado e as transformações do capitalismo na era pós-industrial alteraram o enquadramento dos percursos profissionais (Boltanski e Chiapello, 1999; Lash e Urry, 1987). Nas cinzas do regime fordista, e da sua relação salarial paradigmática, tem-se desenvolvido um modelo "flexível" ou pós-fordista (Harvey, 2000), movimento potenciado pelos avanços tecnológicos e pela redefinição defensiva dos estados, concretizada na privatização dos recursos públicos e na adoção de soluções orientadas para o mercado (Pierson, 2003).

Os desenvolvimentos tecnológicos das últimas décadas e a mundialização 
da economia conduziram à reestruturação do trabalho à escala global. Sob um enquadramento jurídico mais favorável, os processos de reestruturação e deslocalização (com consequentes despedimentos) assumem um papel importante nas estratégias gestionárias de maximização do lucro e de enfraquecimento do poder dos trabalhadores. Flexibilidade tornou-se o conceito-chave para entender a reorganização da produção, as estruturas organizacionais horizontais e o alastramento da insegurança laboral pela estrutura ocupacional (Atkinson, 2010). Efetivamente, tem sido observado que a nova lógica de lean production está a irradiar da periferia para o centro (Castel, 2012; Estanque, 2009).

A participação feminina no mercado de trabalho intensificou-se, embora esteja frequentemente associada a contextos de precariedade, subalternidade e acentuada desigualdade salarial (Casaca, 2010). Atividades outrora asseguradas pelas mulheres na esfera doméstica foram mercantilizadas, estando o crescimento do "terceiro setor" relacionado com a retração do estado-providência (Antunes e Alves, 2004). Neste contexto, tem sido observada a segmentação da força de trabalho em dois grupos: um núcleo duro de quem se espera adaptabilidade e disponibilidade para reciclar planos de carreira, em troca de segurança no emprego; e uma franja periférica de trabalhadores em modalidades tendencialmente precarizadas de emprego (a tempo parcial, por conta própria, subcontratado ou on-call, etc.), e sob a ameaça permanente do desemprego (Casaca, 2010; Matos, 2013: 167-168).

A diferenciação entre trabalho "seguro" e "inseguro" manifesta-se de formas diversas: nos países centrais, resulta em diferenças ao nível da segurança na relação laboral, da vulnerabilidade face aos despedimentos e da exposição às modalidades precárias de trabalho; nos países periféricos, a insegurança está frequentemente ligada à informalidade, ao trabalho não declarado, clandestino, em condições inseguras e, por vezes, insalubres (Kalleberg, 2009). A pesquisa demonstra que a insegurança laboral está associada ao agravamento das desigualdades na esfera do trabalho e à criação de uma zona cada vez mais numerosa de empregos precários e tendencialmente pouco qualificados (Barbieri, 2009; DiPrete et al., 2006).

Evidentemente que a incerteza associada ao trabalho não é nova. Como demonstram Goodwin e O'Connor (2015), mesmo no contexto fordista do pós-guerra subsistiam fases de instabilidade laboral, embora mais circunscritas ao início da vida profissional. Mas as dinâmicas recentes conferiram contornos distintos à instabilidade no mundo do trabalho. Desde logo, porque a desregulamentação das relações laborais e a generalização das formas precarizadas de emprego quebraram as expectativas de linearidade e estabilidade associadas às trajetórias profissionais e às expectativas de mobilidade social. Por outro lado, porque a persistência da precariedade laboral tende a cristalizar-se num estrato infrassalarial na divisão do trabalho (precariado) que transporta a insegurança para outras esferas da vida social (Castel, 2012; Matos e Domingos, 2012; Matos, Domingos e Kumar, 2010).

\section{Trajetórias profissionais em Portugal: um breve enquadramento}

O contexto económico e político-institucional que enquadra os percursos profissionais em Portugal tem características singulares e distintas face ao contexto 
da Europa Central. Apesar do impulso industrial da década anterior, até à década de 1960 Portugal permanecia um país essencialmente agrícola, condição idealizada pela mitologia ruralista do Estado Novo (Rosas, 2001). Predominavam a Norte a pequena propriedade e a agricultura familiar, enquanto no Sul os grandes latifúndios definiam uma organização socioeconómica polarizada, em que os assalariados agrícolas constituíam o grosso da população ativa, reforçado sazonalmente por trabalhadores migratórios das regiões de agricultura familiar (Baptista, 1994). A situação dos assalariados rurais era particularmente frágil, não só pela sazonalidade do emprego, como pela informalidade da relação laboral, pela dureza das condições de trabalho e pelas baixas remunerações. Com a mecanização do trabalho a polarização social dos campos do Sul acentuou-se (Carmo, 2007). Neste contexto, as assimetrias de género eram agudas, tendo as mulheres uma relação extremamente precarizada com o trabalho (Pina-Cabral, 1986).

Face à supressão violenta dos sindicatos livres e sem mecanismos de concertação social, os trabalhadores estavam à mercê da boa vontade do estado (Patriarca, 1994). Aliás, após a II Guerra Mundial, sob o "perigo" da proletarização reforçaram-se os poderes patronais, passando o estado a intervir o mínimo possível na regulação de salários e condições de trabalho (Patriarca, 1994).

Com o crescimento industrial da década de 1960 multiplicaram-se as oportunidades de trabalho no litoral, aí afluindo muitos trabalhadores rurais em busca de melhores remunerações e de emprego estável (Barreto, 2005). Simultaneamente, a recuperação económica da Europa Ocidental atraía centenas de milhares de portugueses (Baganha, 1993). Até 1973, essas duas dinâmicas obviaram a que se registassem problemas de desemprego relevantes (Baganha, 1994; Rodrigues, 1985).

Com o 25 de Abril de 1974 desencadearam-se profundas alterações no contexto sociopolítico e na regulação do mercado de trabalho. As lutas sociais culminaram na ocupação de terras, dando origem aos processos de coletivização da terra (Reforma Agrária) e de nacionalizações. Foi erigido um edifício jurídico que garantiu direitos cívicos e laborais fundamentais e aboliu formas explícitas de discriminação das mulheres que vigoravam durante o Estado Novo (Monteiro, 2010). Embora frágil, o estado-providência emergente tinha aspirações universalistas e redistributivas. As suas fragilidades foram sendo colmatadas por uma sociedade-providência forte, i.e., redes informais (familiares, vizinhança e outras) que providenciam suporte aos indivíduos (Portugal, 2014).

A regulação do trabalho introduzida logo em 1974 diminuiu drasticamente o emprego informal até aí predominante. O contrato de trabalho por tempo indeterminado tornou-se norma, para tal contribuindo a expansão do setor empresarial do estado. Efetivamente, o desenvolvimento da administração pública colocou parte considerável dos trabalhadores sob a alçada de uma relação de emprego público ou equiparado. E contribuiu para moderar o crescimento do desemprego que emergira como consequência da crise económica de 1973 (Rodrigues, 1985), do retorno das ex-colónias de centenas de milhares de pessoas (Pires, 1999) e da agudização dos conflitos pela repartição do rendimento (Lopes, 1996). 
Apesar da institucionalização de uma forma típica de emprego estável, ainda nos anos 70 se operou uma reorientação da criação de emprego para formas precárias, legais ou clandestinas (Rodrigues, 1985). A lei dos contratos de trabalho a prazo surge em 1976 e os anos que se seguem à adesão à CEE em 1986 são marcados pela retração do direito do trabalho (Santos, 1993). Com efeito, o pacote laboral de 1988 introduz medidas de flexibilização do mercado de trabalho e a revisão constitucional de 1989 abriu as portas à reprivatização das empresas nacionalizadas.

As estratégias patronais que visavam contornar a relação salarial típica generalizaram-se nos setores de mão de obra intensiva e sazonal, por vezes contando com a convivência e proximidade entre empregador e trabalhador. Esta situação revelava uma dualidade na sociedade portuguesa entre formas institucionais de regulação fordista e zonas em que persistiam relações de tipo pré-capitalista, manifestas na informalidade das práticas e na legitimação do atropelo à legalidade (Santos, 1993).

A partir da década de 1990, as práticas de flexibilização intensificaram-se no tecido empresarial português, sobretudo porque a sua estratégia competitiva se baseia na redução de custos (Kóvacs e Casaca, 2007). Sob a capa do autoemprego frequentemente se dissimulam situações de trabalho dependente ("recibo verde"), em que o trabalhador é um assalariado precário sem acesso aos direitos associados ao contrato laboral, como a proteção no desemprego e na doença, ou as contribuições do empregador para a segurança social.

A crescente participação feminina no mercado de trabalho é uma transformação profunda na vida social portuguesa nos últimos 50 anos. Tendo sido impulsionada pela escassez de mão de obra masculina, causada pela emigração e pela Guerra Colonial (Baganha, 1993), após 1974 decorreu sobretudo da expansão dos serviços e do emprego público. As mulheres protagonizaram o processo de qualificação académica e profissional das últimas décadas, desempenhando um papel vital nas "funções sociais" do estado. Mas a feminização do emprego ocorreu em paralelo com a flexibilização das relações laborais, sobretudo já no período pós-1974. A fragilização dos vínculos contratuais, a insegurança no emprego ou o trabalho a tempo parcial incidem mais sobre as mulheres, estando, por isso, mais sujeitas a salários baixos, à exclusão de benefícios e proteção social, e a menores oportunidades de carreira. Dados recentes confirmam uma intensificação da preponderância feminina nos setores que oferecem piores remunerações, nomeadamente na indústria têxtil e nos serviços pessoais pouco qualificados (V. Ferreira, 2010).

Um derradeiro aspeto a considerar é a evolução do desemprego. Ao longo da primeira década do século XXI, o fenómeno adquiriu magnitude sem precedentes. Também a sua composição social, etária e sexual se modificou, fruto do impacto da crise económica sobre atividades predominantemente masculinas. Tendo atingido particularmente a população ativa jovem, o desemprego de longa duração tem vindo a aumentar nos escalões etários mais velhos. 


\section{Estratégia metodológica, hipóteses e dados}

A história recente e a posição semiperiférica de Portugal no contexto da economia mundial tornam desafiante a conceptualização das trajetórias profissionais. Entre os fatores a considerar estão: a posição da economia portuguesa na divisão internacional do trabalho; o seu modelo de desenvolvimento; a regulação das relações industriais; o modelo de estado-providência e os mecanismos informais de proteção; a estrutura económica e empresarial e a sua abertura ao exterior; e o perfil ocupacional da população ativa (Pinto, 2006: 179).

Em nosso entender, a análise das trajetórias profissionais individuais deve evitar tanto dicotomias simplistas entre modalidades de regulação (pré-fordismo $v s$. fordismo vs. pós-fordismo), como perspetivas deterministas sobre a evolução do mundo do trabalho ou sobre a relação entre qualificações e emprego. As trajetórias profissionais individuais dependerão da estrutura de oportunidades e do enquadramento jurídico-institucional específico do tempo histórico em que os indivíduos estão inscritos, bem como da estrutura dos seus capitais.

A coexistência de um amplo número de trajetórias será um desfecho verosímil da heterogeneidade e instabilidade da regulação estatal, bem como da rápida transformação da estrutura económica. Essa heterogeneidade será patente tanto na comparação entre coortes como no seio de cada coorte etária. ${ }^{1}$ Em todo o caso, é expectável que o trabalho em situação informal seja mais comum em coortes etárias mais velhas, bem como transversalmente em atividades menos qualificadas. É expectável que em coortes mais recentes coexistam trajetórias estáveis, resultantes de situações laborais protegidas, com trajetórias mais instáveis, marcadas pela flexibilização e precarização de emprego.

Os dados utilizados provêm de uma amostra de 1500 homens e mulheres residentes em Portugal Continental. ${ }^{2}$ Trata-se de uma amostra probabilística estratificada, segmentada em três coortes etárias diferentes (nascidos entre 1935-40, 1950-55 e 1970-75).

A trajetória de trabalho e emprego foi auscultada desta forma: "Gostaria agora que falasse sobre o que fez ao longo da vida: os momentos em que estudou e trabalhou ao mesmo tempo, as profissões que exerceu, as mudanças de emprego ou de categoria profissional, os períodos em que esteve em casa ou esteve desempregado(a), etc.". A reconstituição da trajetória, feita em anos a partir dos sete anos de

1 O conceito de coorte etária é central na perspetiva do percurso de vida (Mayer, 2009). Situa os indivíduos relativamente a eventos históricos e à vivência partilhada das fases do desenvolvimento pessoal. É menos ambicioso que o conceito de geração (Mannheim, 1952 [1927]), não integrando elementos sobre as "subjetividades partilhadas" pelos sujeitos que partilham um intervalo de nascimento ou a "experiência" de episódios históricos.

2 Amostra recolhida no âmbito do projeto "Trajetórias Familiares e Redes Sociais" (TFRS) (PTDC/SDE/65663/2006), coordenado por Karin Wall no Instituto de Ciências Sociais da Universidade de Lisboa. Foi feita uma seleção aleatória dos locais amostrais a partir dos códigos postais. Os lares foram escolhidos por random route e em cada lar foi entrevistado o último aniversariante. O trabalho de campo decorreu entre novembro de 2009 e junho de 2010. 
idade, articula a dimensão emprego (i.e. modalidades de relação laboral) com a dimensão trabalho/profissão (i.e. atividades profissionais exercidas ao longo da vida). O indicador utilizado para o emprego combina "situação perante a profissão" e "relação contratual". ${ }^{3}$ Para as atividades profissionais recorremos à Classificação Nacional das Profissões (1994). ${ }^{4}$

Definimos trajetória profissional enquanto sequência de acontecimentos e situações profissionais vividas pelos indivíduos ao longo da vida. Esta definição relaciona os padrões de regularidade das carreiras com as escolhas individuais e com a evolução do sistema de emprego. A trajetória profissional é definida a partir da relação individual com o mercado de trabalho, sendo as modalidades de participação (ou exclusão) relevantes enquanto proxy de integração social.

Com base nos critérios de ocupação e emprego, construímos uma tipologia de trajetórias profissionais, que corresponde à posição dos indivíduos face ao mundo do trabalho entre os 11 e os 35 anos de idade (considerando o total da amostra). Recorremos à multi-channel sequence analysis e ao optimal matching (Gauthier $e$ t al., 2010). A identificação dos padrões da sequência conjunta de trabalho e emprego foi feita através da análise de clusters utilizando o método de Ward. ${ }^{5}$

\section{Um retrato das trajetórias profissionais nas três coortes}

Um primeiro olhar evidencia panoramas diferenciados, tanto na idade com que se entrou no mercado de trabalho, como nas modalidades de emprego predominantes (figura 1 e quadro 1). Na primeira coorte, aos 11 anos de idade um terço dos indivíduos já desempenhava alguma atividade e mais de metade já se encontrava a trabalhar pelos 13 anos. A informalidade marcava tanto o início da vida profissional como todo o período em análise. Trabalhar por conta própria ou criar um pequeno negócio era relativamente comum, sobretudo depois dos 25 anos. Destacavam-se ainda a importância do serviço militar ${ }^{6}$ nos percursos masculinos e o peso do trabalho doméstico nos percursos femininos. O desemprego tinha uma expressão residual.

A entrada no mundo do trabalho foi mais tardia para os indivíduos da segunda coorte. A informalidade predominava ainda entre aqueles que começaram a

3 Foram considerados 11 estados: (1) a trabalhar por conta própria; (2) a trabalhar por conta de outrem, contrato permanente; (3) a trabalhar por conta de outrem, contrato a prazo; (4) a trabalhar por conta de outrem, sem contrato; (5) a trabalhar por conta de outrem, outra situação; (6) a fazer trabalho doméstico; (7) no desemprego; (8) em formação (estudar/formação); (9) na reforma; (10) outras situações; (11) dados insuficientes.

4 Foram usadas as grandes categorias, para um total de 10 estados: (1) quadros, dirigentes e gestores; (2) especialistas das profissões intelectuais e científicas; (3) técnicos de nível intermédio; (4) pessoal administrativo e similares; (5) pessoal dos serviços e vendedores; (6) agricultores e trabalhadores qualificados da agricultura e pescas; (7) operários, artífices e trabalhadores similares; (8) operadores de instalações e máquinas de montagem; (9) trabalhadores não qualificados; (10) fora do mercado de trabalho. O serviço militar é mencionado numa primeira descrição, mas posteriormente considerado como estando fora do mercado de trabalho.

5 Operações realizadas em software R (pacote TraMineR).

6 Na figura em "outras situações". 


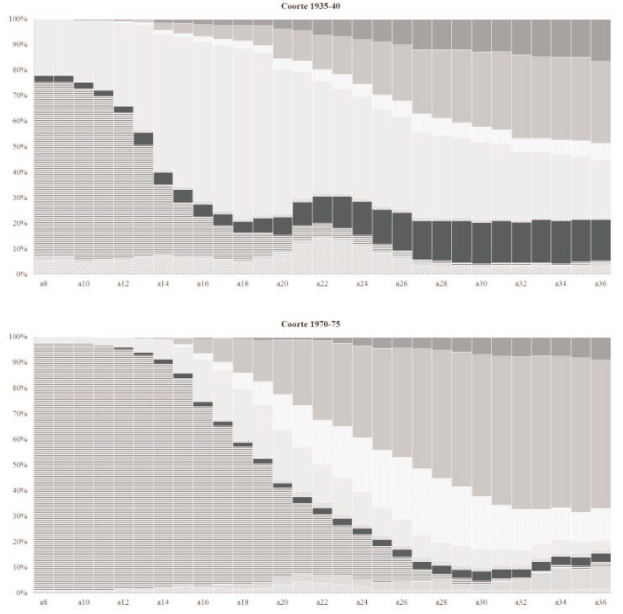

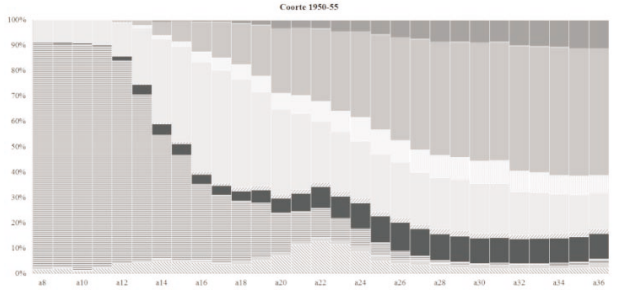

吾 A trabalhar por conta própria

= A trabalhar por conta de outrem, contrato permanente

A trabalhar conta de outrem, contrato a prazo

A trabalhar conta de outrem, sem contrato

A trabalhar conta de outrem, outra situação

- A fazer trabalho doméstico

E Em formação (estudar/formação profissional)

- Na reforma

No Desemprego

Outras situações

Figura 1 Situação no emprego (percentagens acumuladas anuais por coorte)

Fonte: TFRS, 2010.

Quadro 1 Indicadores de emprego, segundo a coorte e o sexo (médias e percentagem)

\begin{tabular}{l|r|r|c|c|c|c|c|c|c}
\hline & \multicolumn{3}{|c|}{ Coorte 1935-40 } & \multicolumn{2}{c|}{ Coorte 1950-55 } & \multicolumn{3}{c}{ Coorte 1970-75 } \\
\cline { 2 - 10 } & $\mathrm{HM}$ & $\mathrm{M}$ & $\mathrm{F}$ & $\mathrm{HM}$ & $\mathrm{M}$ & $\mathrm{F}$ & $\mathrm{HM}$ & $\mathrm{M}$ & $\mathrm{F}$ \\
\hline Idade com que começou a trabalhar & 12,5 & 12,3 & 12,5 & 14,7 & 14,3 & 15,1 & 17,7 & 17,3 & 18,0 \\
Anos de serviço militar & 0,5 & 1,2 & - & 0,4 & 0,9 & - & 0,1 & 0,2 & - \\
Anos como doméstica & 2,8 & - & 4,7 & 2,0 & - & 3,3 & 0,7 & - & 1,1 \\
Anos a trabalhar por conta própria & 2,0 & 2,0 & 2,0 & 1,4 & 1,9 & 1,0 & 0,9 & 1,0 & 0,9 \\
Anos a trabalhar com contrato permanente & 4,5 & 6,2 & 3,3 & 7,8 & 8,6 & 7,2 & 8,4 & 9,1 & 8,0 \\
Anos a trabalhar com contrato a prazo & 1,1 & 1,7 & 0,7 & 1,7 & 1,4 & 1,8 & 3,4 & 3,2 & 3,5 \\
Anos a trabalhar sem contrato & 10,5 & 10,1 & 10,8 & 6,4 & 6,6 & 6,3 & 2,6 & 3,2 & 2,3 \\
Anos no desemprego & 0,2 & 0,2 & 0,2 & 0,3 & 0,3 & 0,3 & 0,8 & 0,6 & 0,9 \\
Percentagem que passou por desemprego & 2,9 & 1,6 & 3,8 & 4,6 & 5,2 & 4,2 & 15,9 & 10,7 & 19,1 \\
(1 ano ou mais) & & & & & & & & & \\
\hline
\end{tabular}

Fonte: TFRS, 2010.

trabalhar na adolescência. Consolidaram-se as situações de assalariamento formalizado, sendo menos frequente a criação do próprio emprego. A partir da segunda década de vida profissional, o contrato estável tornou-se mais comum. Longos períodos de desemprego continuavam a ser raros. Diminuiu o peso relativo do trabalho doméstico entre as mulheres e do serviço militar nos percursos masculinos.

Para a maioria dos indivíduos da coorte de 1970-75, a entrada na vida profissional ocorreu por volta dos 18 anos, em resultado do alongamento das carreiras escolares. O trabalho em situações estáveis generalizou-se. O contrato a prazo 
surgiu como modalidade de contratação relevante e a informalidade persiste nos percursos profissionais mais precoces. O trabalho com contrato precário incidia sobretudo na segunda década de vida profissional. Um em cada seis indivíduos passou por longos períodos de desemprego, situação mais comum entre as mulheres. O trabalho doméstico torna-se residual.

\section{As atividades profissionais}

Em termos das atividades profissionais (grandes grupos agregados) desempenhadas ao longo da vida (figura 2), na coorte de 1935-40 o início do trabalho em idade muito precoce estava associado ao trabalho nos campos. As atividades profissionais mais comuns, a partir da segunda década de vida profissional, eram sobretudo de trabalho manual em pequenas indústrias ou oficinais (pedreiros, carpinteiros, modistas, etc.). No setor terciário, as profissões mais comuns encontravam-se no comércio (lojistas, caixeiros, etc.). Os quadros, as categorias técnicas ou especializadas e o trabalho administrativo tinham um peso muito reduzido.

Na coorte de 1950-55, o trabalho manual na indústria continuou a marcar uma parte significativa dos percursos individuais. $\mathrm{O}$ trabalho industrial em fábrica tornou-se, então, mais relevante. No setor dos serviços, as profissões administrativas tornaram-se mais comuns nos percursos, crescendo também ligeiramente as profissões mais especializadas.
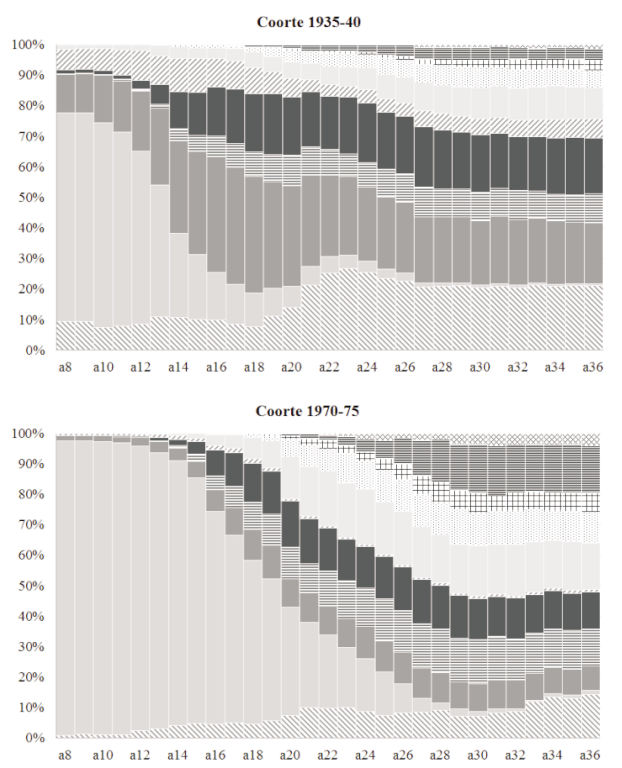

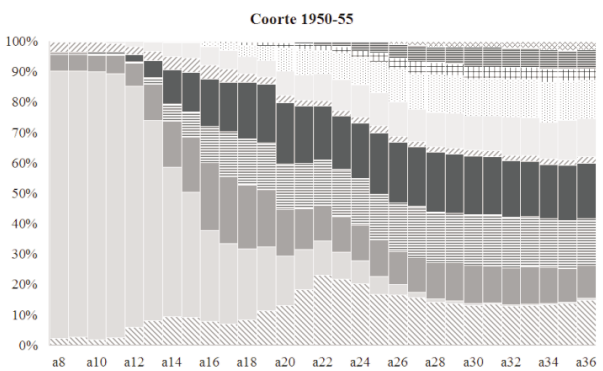

Quadros, Dirigentes e Gestores $\equiv$ Especialistas

Tecnicos e Profissionais de nivel intermedio

Pessoal Administrativo e Similares

Pessoal dos Servicos e Vendedores

Agricultores

Operários, Artifices e Trab. Similares

= Operadores de instalacoes e maquinas e trabalhadores da montagem

- Trabalhadores nao qualificados

Estudantes

Outras

Figura 2 Atividades profissionais (percentagens acumuladas anuais por coorte)

Fonte: TFRS, 2010. 
Os efeitos da terciarização da economia e da qualificação da mão de obra são evidentes nas trajetórias da coorte de 1970-75. A maior parte dos percursos profissionais envolveu desempenho de profissões no comércio e nos serviços. Também as profissões técnicas marcam um conjunto muito significativo de percursos. A qualificação faz-se ainda sentir pelo aumento do número de quadros, dirigentes e gestores, aspeto relacionado com a expansão da administração pública e com a abertura da economia ao exterior, com o estabelecimento de filiais portuguesas de empresas multinacionais nos setores financeiros, comercial e tecnológico. Em sentido contrário, decresceu a importância das profissões rurais e industriais nos percursos profissionais.

\section{Classificação tipológica das trajetórias profissionais}

As trajetórias de emprego estável na indústria são as mais comuns (17,9\%). Desenvolvem-se exclusivamente em pequenas e médias unidades industriais. A entrada no mercado de trabalho ocorre cedo (média: 13,2 anos). Entradas mais tardias estão associadas a situações contratuais tendencialmente estáveis, enquanto ingressos mais precoces na vida ativa estão associados à informalidade, tendendo a estabilizar-se mais tarde. De facto, nos setores industriais, a qualificação e especialização profissional implicava aprendizagem de um ofício junto de mestres mais velhos. Esse "período experimental" estendia-se por algum tempo, ao fim do qual se passava de aprendiz a ajudante ou praticante. À mudança de estatuto correspondia não só o reconhecimento da capacidade profissional, como também uma relação contratual.

As trajetórias de emprego estável nos serviços correspondem a 15,1\% dos casos. Aqui, a atividade profissional tem início por volta dos 17 anos. Em cerca de 1/5 dos casos, o início do percurso profissional é marcado pela informalidade (quando ocorre antes dos 18 anos) ou contratos a termo (em transições mais tardias). Após essa primeira fase, a relação contratual estabiliza-se. As situações de desemprego são ligeiramente mais frequentes neste tipo de trajetória do que na anterior $(8,8 \%$ face a $7,8 \%$ ) e 7,5\% dos indivíduos estiveram em algum momento a exercer trabalho doméstico.

As trajetórias de emprego esporádico correspondem a 14,6\% dos casos. Estes percursos caracterizam-se por uma relação intermitente com o mercado de trabalho. Em média, a entrada neste ocorre em torno dos 17 anos, mas pode ser muito variável ( $\mathrm{DP}=8,7$ anos). Isso permite identificar duas variantes nesta trajetória. Encontram-se aqui as domésticas, que geralmente exerceram alguma atividade profissional remunerada, em geral atividades pouco qualificadas com vínculo laboral informal. Nesse caso, a saída do mercado de trabalho ocorre entre os 19 e os 23 anos, indiciando uma possível sincronização com a transição para a conjugalidade ou para a parentalidade. Um segundo subgrupo corresponde a indivíduos que, apesar de desempenharem sobretudo atividades qualificadas, não conseguem consolidar a sua integração no mercado de trabalho, algo que é evidenciado pela elevada incidência do desemprego (13,3\%).

As trajetórias de emprego precário na indústria e serviços agregam $13,6 \%$ da amostra. Neste tipo de percursos, a atividade profissional inicia-se pelos 15 anos. Em 
Quadro 2 Tipos de trajetórias profissionais

\begin{tabular}{|c|c|c|c|c|c|c|c|c|c|}
\hline & \multicolumn{5}{|c|}{ Anos em que esteve em cada estado } & \multirow{4}{*}{$\begin{array}{c}\text { Desemp. } \\
\begin{array}{c}(>=1 \text { ano }) \\
(\%)\end{array} \\
7,8\end{array}$} & \multirow{4}{*}{$\begin{array}{c}\begin{array}{c}\text { Alguma } \\
\text { vez em } \\
\text { trabalho } \\
\text { domést. } \\
(\%)\end{array} \\
1,1\end{array}$} & \multirow{4}{*}{\begin{tabular}{|c}
$\begin{array}{c}\text { Idade } \\
1 .^{\circ} \text { empr. }\end{array}$ \\
$\begin{array}{r}13,2 \\
3,1\end{array}$
\end{tabular}} \\
\hline & & \multicolumn{4}{|c|}{ Emp. por conta de outrem } & \multirow{3}{*}{$\begin{array}{c}\begin{array}{c}\text { Emp. por } \\
\text { conta } \\
\text { própria }\end{array} \\
0,2 \\
0,9\end{array}$} & & & \\
\hline & & & & Sen & & & & & \\
\hline $\begin{array}{l}\text { Estável na indústria } \\
(17,9 \%)\end{array}$ & $\begin{array}{l}\text { Média } \\
\text { DP* }^{*}\end{array}$ & $\begin{array}{l}3,3 \\
4,4\end{array}$ & $\begin{array}{l}0,9 \\
2,2\end{array}$ & $\begin{array}{r}16,6 \\
5,0\end{array}$ & $\begin{array}{l}0,1 \\
0,8\end{array}$ & & & & \\
\hline $\begin{array}{l}\text { Estável nos serviços } \\
(15,1 \%)\end{array}$ & $\begin{array}{l}\text { Média } \\
\mathrm{DP}^{*}\end{array}$ & $\begin{array}{l}1,8 \\
2,8\end{array}$ & $\begin{array}{l}1,4 \\
2,5\end{array}$ & $\begin{array}{r}13,3 \\
4,4\end{array}$ & $\begin{array}{l}0,1 \\
0,8\end{array}$ & $\begin{array}{l}0,1 \\
0,4\end{array}$ & 8,8 & 7,5 & $\begin{array}{r}17,4 \\
4,1\end{array}$ \\
\hline $\begin{array}{l}\text { Esporádico } \\
(14,5 \%)\end{array}$ & $\begin{array}{l}\text { Média } \\
\text { DP* }^{*}\end{array}$ & $\begin{array}{l}4,1 \\
4,8\end{array}$ & $\begin{array}{l}0,9 \\
2,4\end{array}$ & $\begin{array}{l}1,2 \\
2,9\end{array}$ & $\begin{array}{l}0,4 \\
1,8\end{array}$ & $\begin{array}{l}0,4 \\
1,7\end{array}$ & 13,3 & 66,1 & $\begin{array}{r}17,1 \\
8,7\end{array}$ \\
\hline $\begin{array}{l}\text { Precário na indústria } \\
\text { e serviços }(13,6 \%)\end{array}$ & $\begin{array}{l}\text { Média } \\
\text { DP* }^{*}\end{array}$ & $\begin{array}{l}3,1 \\
4,3\end{array}$ & $\begin{array}{l}9,1 \\
7,7\end{array}$ & $\begin{array}{l}3,8 \\
5,7\end{array}$ & $\begin{array}{l}1,2 \\
4,5\end{array}$ & $\begin{array}{l}0,6 \\
2,6\end{array}$ & 12,7 & 4,9 & $\begin{array}{r}15,2 \\
4,6\end{array}$ \\
\hline $\begin{array}{l}\text { Informal na indústria } \\
\text { e serviços }(10,3 \%)\end{array}$ & $\begin{array}{l}\text { Média } \\
\text { DP* }^{*}\end{array}$ & $\begin{array}{r}20,3 \\
4,8\end{array}$ & $\begin{array}{l}0,3 \\
0,9\end{array}$ & $\begin{array}{l}1,1 \\
2,6\end{array}$ & $\begin{array}{l}0,1 \\
0,6\end{array}$ & $\begin{array}{l}0,5 \\
1,7\end{array}$ & 4,5 & 7,1 & $\begin{array}{r}12,0 \\
3,4\end{array}$ \\
\hline $\begin{array}{l}\text { Emprego informal } \\
\text { desqualif. }(10,1 \%)\end{array}$ & $\begin{array}{l}\text { Média } \\
\text { DP* }^{*}\end{array}$ & $\begin{array}{r}20,2 \\
6,0\end{array}$ & $\begin{array}{l}0,7 \\
2,1\end{array}$ & $\begin{array}{l}1,8 \\
3,6\end{array}$ & $\begin{array}{l}0,1 \\
1,4\end{array}$ & $\begin{array}{l}0,7 \\
2,2\end{array}$ & 6,0 & 4,0 & $\begin{array}{r}11,0 \\
3,5\end{array}$ \\
\hline $\begin{array}{l}\text { Estável qualificado } \\
(9,9 \%)\end{array}$ & $\begin{array}{l}\text { Média } \\
\mathrm{DP}^{\star}\end{array}$ & $\begin{array}{l}0,9 \\
2,3\end{array}$ & $\begin{array}{l}1,9 \\
2,4\end{array}$ & $\begin{array}{r}10,3 \\
3,8\end{array}$ & $\begin{array}{l}0,1 \\
0,9\end{array}$ & $\begin{array}{l}0,1 \\
0,7\end{array}$ & 4,7 & 0,0 & $\begin{array}{r}21,2 \\
4,2\end{array}$ \\
\hline $\begin{array}{l}\text { Por conta própria } \\
(8,6 \%)\end{array}$ & $\begin{array}{l}\text { Média } \\
\text { DP* }\end{array}$ & $\begin{array}{l}6,0 \\
5,8\end{array}$ & $\begin{array}{l}0,8 \\
2,1\end{array}$ & $\begin{array}{l}1,0 \\
2,4\end{array}$ & $\begin{array}{l}0,2 \\
1,3\end{array}$ & $\begin{array}{r}12,4 \\
5,1\end{array}$ & 2,3 & 1,6 & $\begin{array}{r}13,8 \\
5,1\end{array}$ \\
\hline
\end{tabular}

*Desvio-padrão. Fonte: TFRS, 2010.

cerca de $1 / 5$ dos casos, os primeiros anos são marcados pela informalidade, mais comum quando a entrada na vida ativa ocorre antes dos 18 anos. Destaca-se aqui a duração do trabalho com contrato a prazo, independentemente do grupo profissional em que os indivíduos se integram (média: 9,1 anos; DP: 7,7 anos). Embora se encontrem casos em todos os grupos profissionais, predominam os serviços pessoais. Num terço dos casos a relação laboral consolida-se após longo período de contrato a termo. A experiência do desemprego é comum nesta trajetória (12,7\%).

A quinta trajetória mais comum é a de emprego informal na indústria e nos serviços $(10,3 \%)$. Nesta trajetória, os períodos formativos são mínimos e a entrada na vida ativa ocorre em idades muito precoces (média: 12 anos). Nos primeiros anos é ainda relevante o trabalho na agricultura. A partir da segunda década de vida profissional predominam as atividades no setor secundário e nos serviços. Estes percursos distinguem-se pela informalidade, i.e., o trabalho em esquemas de emprego desprotegido. As transições para situações de maior estabilidade são tardias e correspondem a um curto período dentro da nossa janela de observação. $\mathrm{O}$ trabalho doméstico tem algum relevo (7,1\%) e a incidência do desemprego ébaixa (4,5\%).

As trajetórias de emprego informal desqualificado englobam 10,1\% da amostra. Distinguem-se pela precocidade da entrada na vida profissional (média: 11 anos) e pela informalidade da relação laboral. É invulgar que estes indivíduos acedam a situações contratuais mais estáveis ou progridam para atividades mais qualificadas. Em apenas 1/5 dos casos transitam para situações de estabilidade contratual, 
geralmente nos serviços pessoais. Estas trajetórias distinguem-se ainda pela predominância de profissões desqualificadas (empregada de limpeza, ajudante de cozinha, estafeta, etc.). A incidência do desemprego cifra-se nos 6,0\% e o envolvimento no trabalho doméstico em $4,0 \%$.

As trajetórias de emprego estável qualificado compreendem 9,9\% dos casos. É a trajetória em que a transição para a vida profissional ocorre mais tarde (média: 21,2 anos). Em geral, o assalariamento sem termo surge logo na primeira experiência profissional, mas cerca de $20 \%$ dos casos incluem períodos de emprego com contrato a prazo ou em situação informal antes da estabilização da situação contratual. Neste tipo de trajetória encontramos trabalhadores com profissões altamente qualificadas e técnicos profissionais de nível intermédio. É baixa a incidência de desemprego de longa duração e o trabalho doméstico é residual.

As trajetórias de emprego por conta própria envolvem $8,6 \%$ da amostra. A entrada na vida ativa ocorre em idade bastante jovem (média: 13,8 anos) associando-se a percursos formativos curtos. Os resultados confirmam, aliás, outras investigações que observaram os baixos recursos qualificacionais dos empresários portugueses (Costa, Machado e Almeida, 2007). Saliente é ainda o facto de estes indivíduos terem, na sua maioria, passado por situações de emprego assalariado informal antes de encetarem atividade independente ou criado a sua empresa. No calendário de entrada na vida ativa e no tipo de atividades profissionais exercidas, estas trajetórias assemelham-se às de emprego informal na indústria e serviços. Encontramos aqui os proprietários das pequenas indústrias, oficinas ou estabelecimentos comerciais, que constituem, aliás, o grosso do patronato em Portugal. É neste tipo de trajetória que a ocorrência de desemprego é menor $(2,3 \%)$.

\section{Trajetórias profissionais em função da coorte e do género}

A comparação entre coortes etárias revela diferenças significativas na distribuição das trajetórias de trabalho e emprego (figura 3). Na coorte de 1935-40 predominam as trajetórias de emprego informal na indústria e nos serviços $(20,0 \%)$, de emprego esporádico (20,0\%), de emprego informal desqualificado $(15,9 \%)$, e de trabalho por conta própria $(12,1 \%)$.

Na coorte de 1950-55 são mais comuns as trajetórias de emprego estável (em conjunto somam $43,3 \%$ ). São também mais frequentes as trajetórias de emprego precário (13,3\%). Em sentido oposto, têm menos peso as trajetórias de emprego informal (somam $20,6 \%)$, de emprego esporádico $(8,1 \%)$ e de emprego por conta própria $(8,5 \%)$.

Na coorte de 1970-75, as trajetórias de emprego estável são claramente maioritárias (somam $58,8 \%$ ). As trajetórias de emprego estável qualificado têm um peso crescente $(17,1 \%)$, mas ficam aquém das trajetórias de emprego precário $(18,1 \%)$. As trajetórias de emprego esporádico mantêm-se relevantes (10,3\%). A informalidade é minoritária (no total 7,1\% dos indivíduos). A tendência global de assalariamento é patenteada pela reduzida expressão das trajetórias de emprego por conta própria $(5,0 \%)$. 


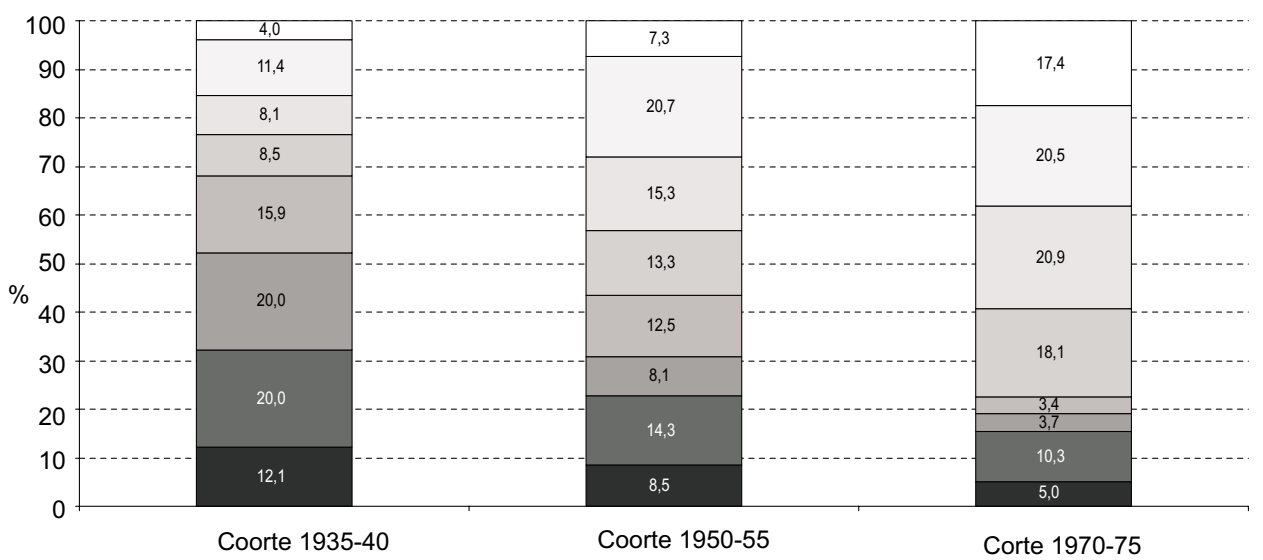

Emprego por conta própria

$\square$ Emprego esporádico

$\square$ Emprego informal na indústria e serviços

Emprego informal desqualificado

Figura 3 Tipos de trajetórias profissionais segundo a coorte (\%)

Comparação entre coortes: $\chi 2(14)=241,679, p<0,001$; $\vee$ de Cramer $=0,284$ Fonte: TFRS, 2010

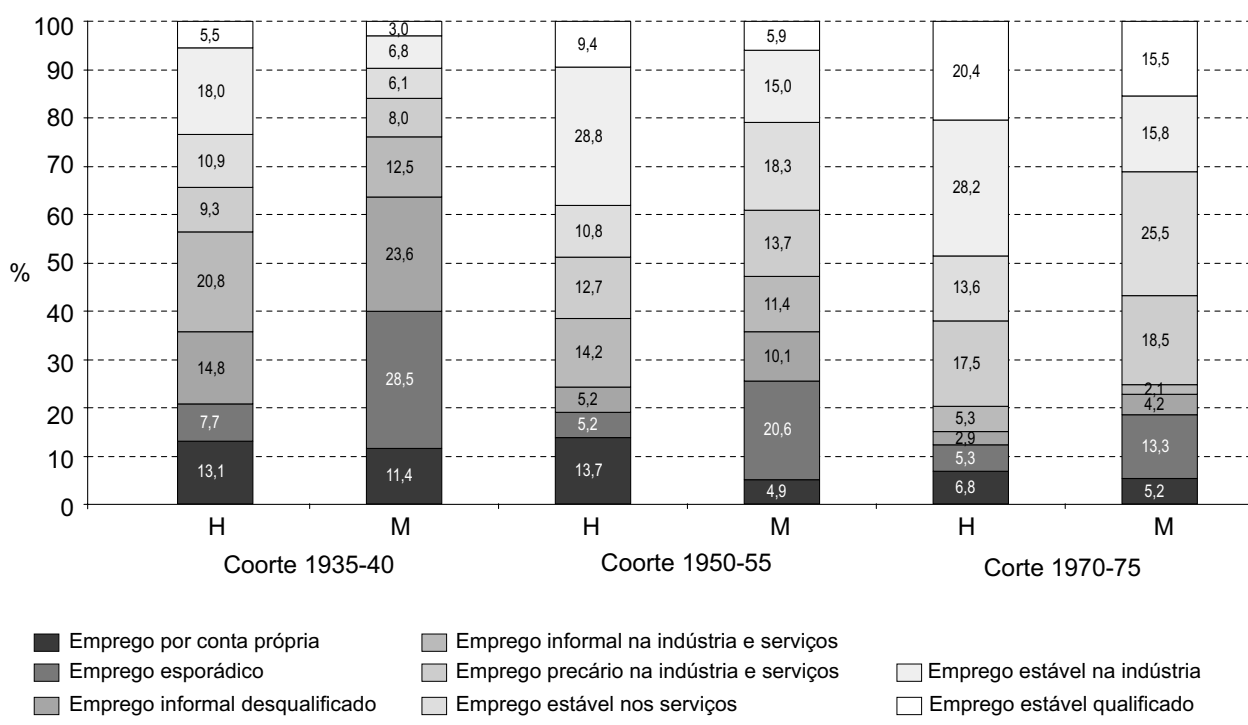

Figura 4 Tipos de trajetórias profissionais segundo a coorte e o género (\%)

Comparação por sexo (coorte 1935-40): $\chi 2(7)=49,329, p<0,001$; $\vee$ de Cramer $=0,333$ Comparação por sexo (coorte 1950-55): $\chi_{2}(7)=54,907, p<0,001 \cdot \mathrm{V}$ de Cramer $=0,326$ Comparação por sexo (coorte 1970-75): $\chi 2(7)=32,895, p<0,001 ; \mathrm{V}$ de Cramer $=0,248$ Fonte: TFRS, 2010 
As trajetórias profissionais são fortemente genderizadas (figura 4). Nos homens nascidos entre 1935-40 e 1950-55 são mais comuns as trajetórias de emprego informal e de emprego estável na indústria. Entre as mulheres nascidas entre 1935-40 predominam as trajetórias de emprego informal desqualificado e de emprego esporádico. Nas mulheres da coorte de 1950-55 prevalecem as trajetórias de emprego estável nos serviços e na indústria, embora o emprego esporádico se mantenha relevante. Na coorte de 1970-75, são mais frequentes, entre os homens, as trajetórias de emprego estável na indústria, de emprego estável qualificado e de emprego precário. Entre as mulheres desta coorte, as trajetórias de emprego estável nos serviços é a mais comum, seguida do emprego precário e de outras modalidades de emprego estável (na indústria e qualificado).

\section{Padrões de associação entre trajetórias profissionais, coorte, género e classe social}

De forma a melhor explorar a associação entre origens sociais, coorte e género recorreu-se a uma análise multivariada, a análise de correspondências múltiplas. Foram incluídas na análise as variáveis "nível de escolaridade do próprio" (cinco categorias), "classe social do grupo doméstico de origem" (utilizando a versão de cinco categorias da tipologia ACM - Costa, Machado e Almeida, 2007), "tipo de trajetória de trabalho e emprego" (oito categorias). "Sexo" e "coorte" foram combinados numa variável com seis categorias (figura 5). ${ }^{7}$

A primeira dimensão (eixo horizontal) distribui as trajetórias profissionais da estabilidade qualificada à informalidade desqualificada. A dispersão das categorias do nível de escolaridade do próprio acompanha este padrão (dos níveis mais baixos aos mais elevados). A segunda dimensão (eixo vertical) dispõe as mesmas trajetórias de acordo com a coorte etária e o sexo. A distribuição do grupo doméstico de origem densifica a interpretação e permite identificar uma série de perfis de associação.

O primeiro perfil associa mulheres da coorte mais velha, baixas habilitações e trajetórias de emprego informal desqualificado. O segundo perfil associa homens da coorte de 1935-40 e mulheres da coorte de 1950-55, em ambos os casos com origens entre trabalhadores independentes, às trajetórias de emprego por conta própria, de emprego informal e de emprego esporádico. Um terceiro perfil associa homens de origem operária da coorte de 1950-55 às trajetórias de emprego estável na indústria. Um quarto perfil congrega indivíduos da coorte mais recente, com origens entre empregados executantes e níveis intermédios de escolaridade, trajetórias de emprego estável nos serviços e emprego precário. Por fim, um quinto perfil associa trajetórias de emprego estável qualificado a indivíduos que completaram o ensino superior e com origens nos grupos sociais com mais capital cultural (profissionais técnicos e de enquadramento), independentemente da coorte etária.

7 Uma solução a duas dimensões revelou-se a mais adequada. As duas dimensões apresentam níveis de consistência interna aceitáveis (respetivamente 0,747 e 0,510) e valores de inércia adequados (respetivamente 0,569 e 0,405 ). 


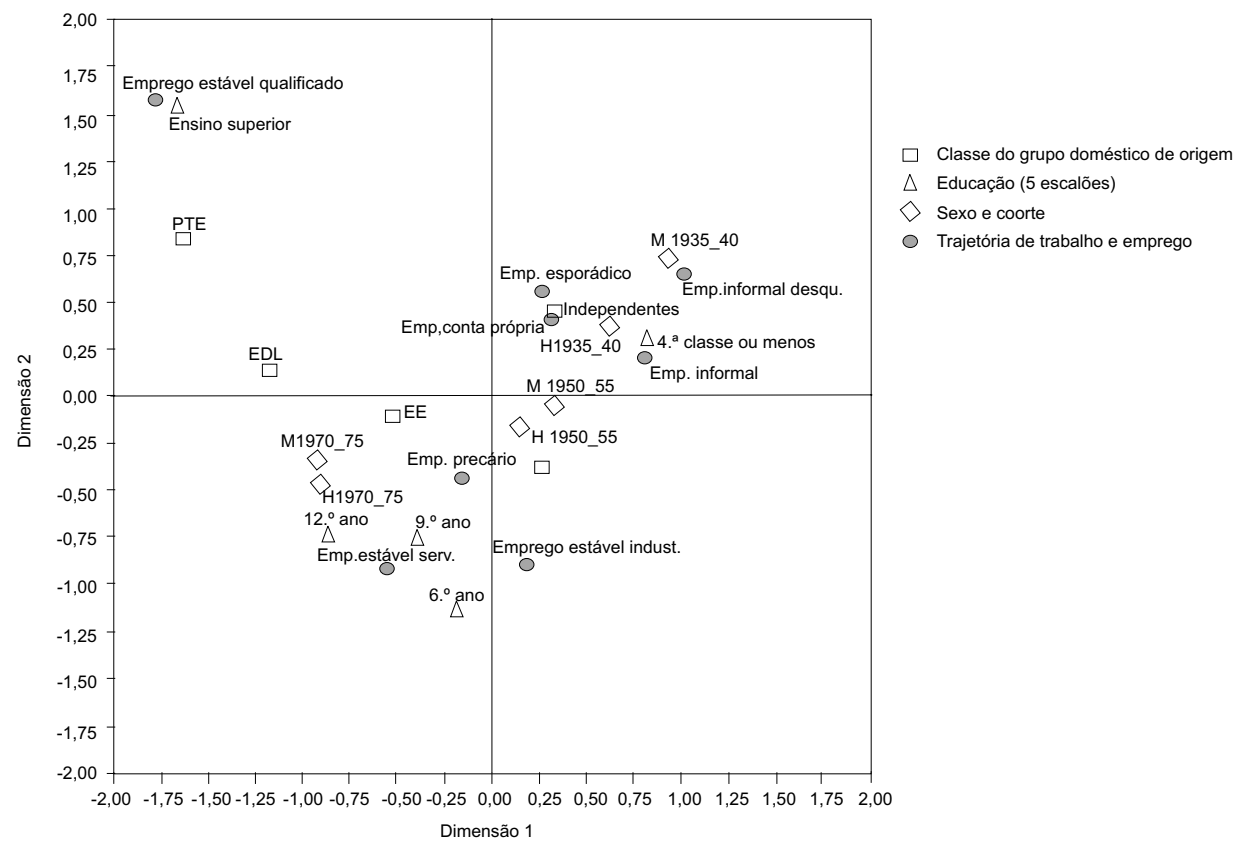

Figura 5 Análise de correspondências múltiplas das trajetórias profissionais

\section{Síntese conclusiva}

Neste artigo propusemos uma leitura holística das trajetórias profissionais individuais, enquanto um todo integrado de transições, articulando contextos de profissionalização e modalidades de emprego. Essa estratégia permitiu identificar trajetórias típicas e reconstruir experiências profissionais em diferentes contextos históricos. Identificámos, assim, oito tipos de trajetórias profissionais com pesos diferenciados, que dão conta da dinâmica da estrutura produtiva que ocorreu na sociedade portuguesa ao longo das últimas décadas: estável na indústria, estável nos serviços, esporádico, precário na indústria e serviços, informal na indústria e serviços, informal desqualificado, estável qualificado e por conta própria.

Esta heterogeneidade das trajetórias profissionais resulta da célere transformação da estrutura económica e da sua crescente abertura ao estrangeiro, sobretudo a partir da década de 1960 . O peso do trabalho agrícola, muitas vezes desempenhado em regime de pluriatividade, foi significativo até há poucas décadas. Comparativamente com outras sociedades da Europa Ocidental, a industrialização portuguesa foi tardia, mobilizou parte menos significativa da força de trabalho e foi rapidamente seguida de uma terciarização. Por outro lado, o modelo de regulação salarial/laboral fordista apenas se impôs em Portugal com a Revolução. A "normalização estatal" conduziu a uma "normalização contratual", tendo sido posteriormente criadas instâncias formais de diálogo social (A. C. Ferreira e 
Costa, 1999: 155; Santos, 1993: 33). No entanto, ao longo das últimas duas décadas, a evolução da regulação estatal sobre o mercado de trabalho tem favorecido a flexibilização das relações laborais.

Muito embora as trajetórias informais predominem na coorte mais velha e as trajetórias estáveis prevaleçam nas duas coortes mais recentes, seria precipitado associar linearmente coortes/períodos históricos e tipos de trajetórias. Nas coortes mais recentes, a heterogeneidade das trajetórias confirma a coexistência das diferentes lógicas regulatórias. Mesmo na coorte mais recente é possível identificar percursos que atestam a importância da economia informal e vestígios de regimes de regulação pré-fordista. Pinto (2006: 183) observou que esses são ainda fatores estruturais e estruturantes das relações económicas em Portugal, resultando na produção alargada de formas de "integração desqualificante". Há também um número crescente de percursos profissionais marcados pela instabilidade, situação decorrente do processo de precarização laboral.

No caso português, a transição entre um regime de produção fordista e pós-fordista é um processo sujeito a antinomias, contradições e fugas para a frente, que em muito resultam da persistência de uma sociedade dualista onde coabitam setores modernos e competitivos com estruturas económicas ultrapassadas (Matos, 2013: 239-241). Isso traduz-se na assimetria das biografias profissionais. É notória a segmentação entre trajetórias com diferentes graus de vulnerabilidade contratual, i.e. a fragmentação do mercado de trabalho entre ativos "nucleares" e "periféricos" (Casaca, 2010).

Na comparação entre coortes, destaca-se a evolução da idade com que se entra no mercado de trabalho. Permanecendo desigual, essa transição é, em geral, mais tardia, por via do alargamento e da democratização do acesso ao ensino. Mas a distribuição dos capitais escolares em cada coorte é um elemento chave para perceber o leque de opções profissionais e de modalidades de emprego que se colocam aos indivíduos. São os indivíduos com mais capitais à partida que tendem a acumular maiores recursos, sobretudo culturais, ao longo das suas trajetórias individuais. Isso contribui para uma distanciação entre percursos, manifesta no calendário das transições, nas ocupações a que se dedicam os indivíduos, no prestígio das profissões que desempenham e na própria estabilidade da trajetória profissional percorrida.

Neste sentido, as trajetórias profissionais têm inscritas marcas da desigualdade de classe e revelam-se altamente permeáveis às lógicas de reprodução, facto em si mesmo revelador da persistência de fortes desigualdades estruturais (Carmo, Carvalho e Cantante, 2015). Essas lógicas são particularmente evidentes entre os descendentes de operários, predominantes nas trajetórias de emprego estável na indústria, e entre os de profissionais de enquadramento, que se destacam nas trajetórias de emprego estável qualificado. Uma lógica de mobilidade qualificante é mais notória entre os descendentes de empresários e de empregados executantes, enquanto o acesso às trajetórias de emprego estável qualificado evidencia sinais de fechamento social. De facto, se nas coortes mais velhas as habilitações ao nível do secundário permitiam acesso a essas trajetórias, já não é assim na coorte mais recente. Aquele processo não pode ser dissociado da autorregulação de alguns 
grupos ocupacionais e da difusão de modelo "profissional" no mundo do trabalho (Gonçalves, 2007-2008).

A reconfiguração das trajetórias de emprego esporádico merece realce. $\mathrm{Na}$ coorte mais recente, estes percursos podem ser concebidos como experimentais, lúdicos ou orientados para o lazer e a realização pessoal (Guerreiro e Abrantes, 2005). Todavia esses padrões, resultantes de processos de reflexividade social, são assimetricamente distribuídos e entrelaçam-se com as origens sociais, os percursos de escolaridade, as oportunidades e condições de emprego, os modelos culturais, os papéis de género e as redes de apoio formais e informais. Hipótese alternativa é que sejam estratégias de adaptação e redução de expectativas face ao futuro, traduzidas em novas formas de encarar o trabalho e o consumo assentes na satisfação das necessidades pessoais de curto prazo (Bauman, 2005). Assim entendidas ilustrariam a "morte social" decorrente do défice de inscrição nas formas coletivas de proteção associadas ao trabalho (Castel, 2013). A sua composição expõe, aliás, a transversalidade dos processos de corrosão da "sociedade salarial" e a redefinição de fronteiras entre grupos sociais ou "zonas" de integração social, vulnerabilidade e desafiliação (Castel, 2012; Paugam, 2000).

$\mathrm{O}$ vínculo estrutural entre domesticidade feminina e carreira masculina, característico do regime fordista, não se observa na realidade portuguesa. Era a informalidade das trajetórias femininas que contribuía para a sua invisibilidade. Não obstante, a trajetória de emprego esporádico revela percursos marcados pela relação intermitente com o mercado de trabalho, passíveis de interrupção por maternidade ou para prestação de cuidados a familiares. Nesses casos, o trabalho doméstico servia de retaguarda face à exclusão do mercado de trabalho. Em alguns contextos, seria uma estratégia conjugal de uma classe operária mais qualificada capaz de assegurar o modelo de homem ganha-pão e mulher doméstica (ver: Almeida, 1993: 176-179).

As trajetórias profissionais de homens e mulheres parecem convergir na coorte mais recente. Para tal contribuíram a regulamentação institucional do emprego, o processo de qualificação das últimas décadas e a preponderância das mulheres nas "funções sociais" na administração pública. Daí resultou alguma aproximação no acesso ao emprego estável. No entanto, a descoincidência entre a maior qualificação das mulheres e o predomínio dos homens em trajetórias de emprego qualificado revela a persistência de fortes desigualdades de género no mercado de trabalho.

\section{Referências bibliográficas}

Almeida, Ana Nunes de (1993), A Fábrica e a Família. Famílias Operárias no Barreiro. Barreiro, Câmara Municipal do Barreiro.

Antunes, R., e G. Alves (2004), “As mutações no mundo do trabalho na era da mundialização do capital", Educação \& Sociedade, 25, pp. 335-351.

Atkinson, W. (2010), Class, Individualization, and Late Modernity in Search of the Reflexive Worker, Houndsmill, Basingstoke, Hampshire, Palgrave Macmillan. 
Baganha, M. I. (1993), "Principais características e tendências da emigração portuguesa”, em AA.VV. (orgs.), Estruturas Sociais e Desenvolvimento, vol. I, Lisboa, Editorial Fragmentos / APS, pp. 819-835.

Baganha, M. I. (1994), “As correntes emigratórias portuguesas no século XX e o seu impacto na economia nacional", Análise Social, XXIX (128), pp. 959-980.

Baptista, F. O. (1994), “A agricultura e a questão da terra - do Estado Novo à Comunidade Europeia", Análise Social, XXIX (128), pp. 907-921.

Barbieri, P. (2009), "Flexible employment and inequality in Europe", European Sociological Review, 25 (6), pp. 621-628, DOI: 10.1093/esr/jcp020

Barreto, A. (2005), “Mudança social em Portugal, 1960-2000”, em António Costa Pinto (coord.), Portugal Contemporâneo, Lisboa, Publicações Dom Quixote, pp. 137-162.

Bauman, Z. (2005), Work, Consumerism and the New Poor, Maidenhead, Open University Press (2. ${ }^{a}$ edição).

Boltanski, L., e E. Chiapello (1999), Le Nouvel Esprit du Capitalisme, Paris, Gallimard.

Bradley, H., M. Erickson, C. Stephenson, e S. Williams (2000), Myths at Work, Cambridge, Polity Press.

Carmo, Renato Miguel do (2007), “As desigualdades sociais nos campos: o Alentejo entre as décadas de 30 e 60 do século XX", Análise Social, XLII (184), pp. 811-835.

Carmo, Renato Miguel do, M. Carvalho, e F. Cantante (2015), “The persistence of class inequality: the Portuguese labour force at the turn of the millennium", Sociological Research Online, 20 (4), disponível em: http://www.socresonline.org.uk/20/4/16.html (última consulta em janeiro de 2016).

Casaca, Sara Falcão (2010), "A (des)igualdade de género e a precarização do emprego", em Virgínia Ferreira (org.), A Igualdade de Mulheres e Homens no Trabalho e no Emprego em Portugal. Políticas e Circunstâncias, Lisboa, Comissão para a Igualdade no Trabalho e no Emprego.

Castel, R. (2012), Les Métamorphoses de la Question Sociale. Une Chronique du Salariat, Paris, Gallimard.

Castel, R. (2013), La Montée des Incertitudes. Travail, Protections, Statut de l'Individu, Paris, Editions du Seuil.

Costa, António Firmino da, Fernando Luís Machado, e João Ferreira de Almeida (2007), "Classes sociais e recursos educativos: uma análise transnacional", em António Firmino da Costa, Fernando Luís Machado e Patrícia Ávila (orgs.), Sociedade e Conhecimento: Portugal no Contexto Europeu, vol. II, Oeiras, Celta Editora.

DiPrete, T. A., D. Goux, E. Maurin, e A. Quesnel-Vallee (2006), “Work and pay in flexible and regulated labor markets: A generalized perspective on institutional evolution and inequality trends in Europe and the U.S.", Research in Social Stratification and Mobility, 24 (3), pp. 311-332.

Estanque, Elísio (2009), “Diferenças sociais de classe e conflitualidade social”, em M. Lages e A. T. Matos (orgs.), Portugal Intercultural. Razão e Projecto, Lisboa, CEPCEP (Universidade Católica Portuguesa) / ACIDI, pp. 123-176.

Ferreira, V. (2010), “A evolução das desigualdades entre salários masculinos e femininos: um percurso irregular", em Virginia Ferreira (org.), A Igualdade de Mulheres e Homens no Trabalho e no Emprego em Portugal. Políticas e Circunstâncias, Lisboa, Comissão para a Igualdade no Trabalho e no Emprego, pp. 139-190. 
Ferreira, A. C., e H. A. Costa (1999), “Para uma sociologia das relações laborais em Portugal", Revista Crítica de Ciências Sociais, 52-53, pp. 141-171.

Gauthier, J.-A., E. D. Widmer, P. Bucher, e C. Notredame (2010), “Multichannel sequence analysis applied to social science data", Sociological Methodology, 40 (1), pp. 1-38.

Gonçalves, C. M. (2007-2008), “Análise sociológica das profissões: principais eixos de desenvolvimento", Sociologia - Revista da Faculdade de Letras da Universidade do Porto, XVII-XVIII, pp. 177-223.

Goodwin, J., e H. O'Connor (2015), “A critical reassessment of the 'complexity' orthodoxy: Lessons from existing data and youth 'legacy' studies", em P. Kelly e A. Kamp (orgs.), A Critical Youth Studies for the 21st Century, Leiden, Boston, Brill, pp. 38-52.

Guerreiro, Maria das Dores, e Pedro Abrantes (2005), “Como tornar-se adulto: processos de transição na modernidade avançada", Revista Brasileira de Ciências Sociais, 20 (58), pp. 157-175.

Harvey, D. (2000), The Condition of Postmodernity. An Enquiry into the Origins of Cultural Change, Cambridge, MA, Blackwell Publishing.

Kalleberg, A. L. (2009), “Precarious work, insecure workers: Employment relations in transition", American Sociological Review, 74 (1), pp. 1-22.

Kóvacs, Ilona, e Sara Falcão Casaca (2007), “Flexibilidad y desigualdad en el trabajo: tendencias y alternativas europeas", Sociología del Trabajo, 61, pp. 99-124.

Lash, S., e J. Urry (1987), The End of Organized Capitalism, Cambridge, Polity Press.

Lopes, J. de S. (1996), “A economia portuguesa desde 1960”, em António Barreto (org.), A Situação Social em Portugal, 1960-1995, Lisboa, Imprensa de Ciências Sociais, pp. 233-364.

Mannheim, K. (1952 [1927]), “The problem of generations”, em P. Kecskemeti (org.), Essays on the Sociology of Knowledge, Londres, Routledge \& Kegan Paul.

Matos, J. N. (2013), O Operário em Construção. Das Relações Humanas ao Trabalho Temporário, Lisboa, Instituto de Ciências Sociais da Universidade de Lisboa, tese de doutoramento em Sociologia.

Matos, J. N., e N. Domingos (2012), Novos Proletários. A Precariedade entre a "Classe Média" em Portugal, Lisboa, Edições 70 / Le Monde Diplomatique.

Matos, J. N., N. Domingos, e R. Kumar (2010), Precários em Portugal. Da Fábrica ao Call-Center, Lisboa, Edições 70 / Le Monde Diplomatique.

Mayer, K. U. (2009), "New directions in life course research”, Annual Review of Sociology, 35, pp. 413-433, DOI: 10.1146/annurev.soc.34.040507.134619

Monteiro, R. (2010), “Genealogia da lei da igualdade no trabalho e no emprego desde finais do Estado Novo", em Virgínia Ferreira (org.), A Igualdade de Mulheres e Homens no Trabalho e no Emprego em Portugal. Políticas e Circunstâncias. Lisboa, Comissão para a Igualdade no Trabalho e no Emprego, pp. 31-56.

Patriarca, Fátima (1994), "A regulamentação colectiva de trabalho nos primeiros anos do regime corporativo", Análise Social, XXIX (128), pp. 801-839.

Paugam, S. (2000), Le Salarié de la Précarité. Les Nouvelles Formes de l'Intégration Professionnelle, Paris, Presses Universitaires de France.

Pierson, P. (2003), Dismantling the Welfare State? Reagan, Thatcher, and the Politics of Retrenchment, Cambridge e Nova Iorque, Cambridge University Press. 
Pina-Cabral, João de (1986), Sons of Adam, Daughters of Eve. The Peasant Worldview of the Alto Minho (NW Portugal), Oxford, Clarendon Press.

Pinto, José Madureira (2006), “Precarização e relações de sentido no espaço social do trabalho", Sociologia - Revista da Faculdade de Letras da Universidade do Porto, 16, pp. 177-190.

Pires, Rui Pena (1999), “O regresso das colónias”, em F. Bethencourt e K. Chaudhuri (orgs.), História da Expansão Portuguesa, vol. 5, , Lisboa, Círculo de Leitores, pp. 182-196.

Portugal, S. (2014), Família e Redes Sociais. Ligações Fortes na Produção de Bem-Estar, Coimbra, Edições Almedina.

Rodrigues, M. J. (1985), “O mercado de trabalho nos anos 70: das tensões aos metabolismos", Análise Social, XXI (87-88-89), pp. 679-733.

Rosas, Fernando (2001), “O salazarismo e o homem novo: ensaio sobre o Estado Novo e a questão do totalitarismo", Análise Social, XXXV (157), pp. 1031-1054.

Santos, Boaventura de Sousa (1993), “O Estado, as relações salariais o bem-estar social na semiperiferia: o caso português", em Boaventura de Sousa Santos (org.), Portugal. Um Retrato Singular, Porto, Centro de Estudos Sociais / Edições Afrontamento, pp. 17-56.

Vasco Ramos (corresponding author). Doutorado em Sociologia pela Universidade de Lisboa, é atualmente investigador pós-doutorado no Instituto de Ciências Sociais (ULisboa) e membro colaborador do OFAP (Observatório das Famílias e Políticas de Família), Av. Prof. Aníbal de Bettencourt, 9, 1600-189 Lisboa. E-mail: vasco.ramos@ics.ulisboa.pt

Receção: 15 de maio de 2016 Aprovação: 12 de dezembro de 2016

Este trabalho é financiado por fundos nacionais através da FCT - Fundação para a Ciência e a Tecnologia, I.P., no âmbito do projeto de pós-doutoramento SFRH/BPD/116221/2016. 